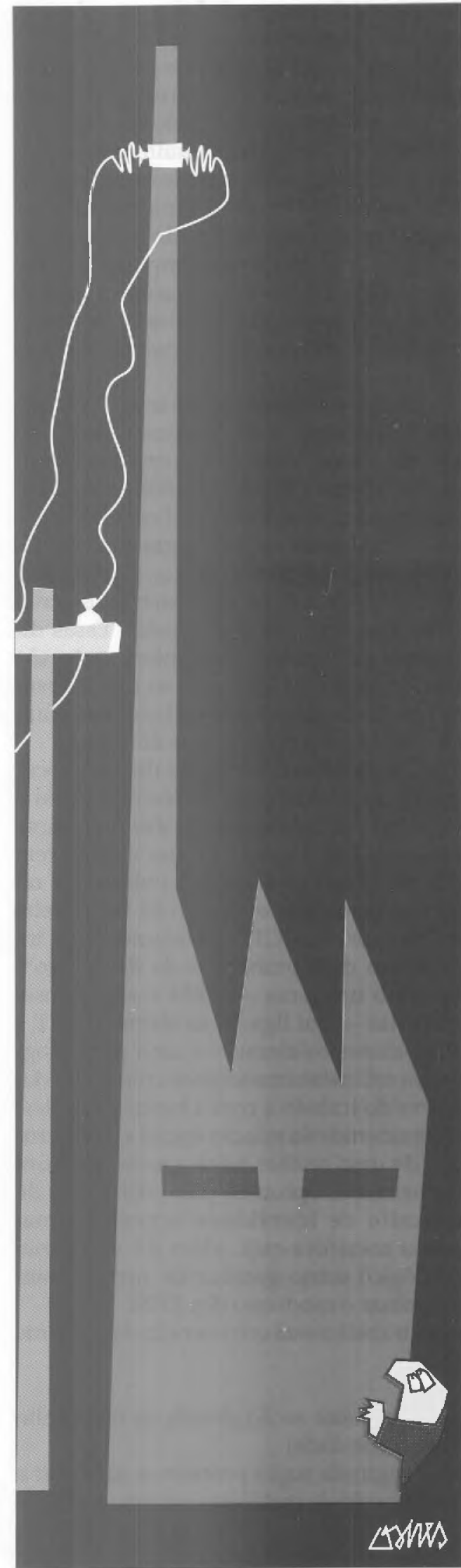

Revista de Administração de Empresas

\section{QUEM TEM MEDO DE ELETROCHOQUE? IDENTIDADE, TERAPIAS CONVULSIVAS E MUDANÇA ORGANIZACIONAL}

\footnotetext{
$\star$ Thomaz Wood Jr.

twood@eaesp.fgvsp.br

it Miguel P. Caldas
}

mcaldas@eaesp.fgvsp.br

O modismo dos Processos Radicais de Mudança (PRM) a partir da metáfora da identidade organizacional e da analogia com a Terapia Eletroconvulsiva (ECT).

The faddism of Radical Change Processes (RCP) through the organizational identity metaphor and the analogy with Electroconvulsive Therapy (ECT).

"Nós năo nos sentimos mais em casa, seja dentro ou fora de nossa pele."

(Jim Harrison, escritor norte-americano)

PALAVRAS-CHAVE:

identidade organizacional, mudança organizacional, mudança radical, metáfora, simbolismo, reengenharia, qualidade total, processo de mudança, consultoria organizaçional, eficácia organizacional, metodologia de mudança.

KEY WORDS:

organizational identity, organizational change, radical change, metaphor, symbolism, reengineering, total quality, change process, organizational consulting, organizational efficacy, change methodology.

+ Mestre e Doutorando em Administração de Empresas na EAESP/FCV e Pesquisador Visitonte na New York University.

si Mestre e Doutorando em Administraçāo de Empresas na EAESP/FCV e Pesquisador Visitante na University of Texas at Austin.

(rae@eaesp.fgvsp.br) Assinatura Email 
1. CAMERON, K., FREEMAN, S., MISHRA, A. Downsizing and redesigning organizations. In: HUBER, G. P., GLICK, W. H. (eds.) Organizational change and redesign. New York: Oxford University Press, 1993.

2. TOMASKO, R. Downsizing: reshaping the corporation for the future. New York: Amacon, 1987.

3. HAMMER, M. Reengineering work: don't automate, obliterate. Harvard Business Review. Boston, v. 68, n. 4, p. 104-12, July/Aug. 1990

4. Re-engineering reviewed. The Economist, London, p. 66, July 2, 1994.

5. CASCIO, W. Downsizing: what do we know? What have we learned? Academy of Management Executive, EUA, v. 7 , n. 1, p. 95-104, 1993.

6. TUSHMAN, M., ROMANELLI, E. Organizational evolution: a metamorphosis model of convergence and reorientation. In: STAW, B. M., CUMMINGS, L. L. (eds.) Research in organizational behavior, v. 7 , Greenwich, CT: JAI Press, 1985 , p. 171-222; MILLER, D., FRIESEN, P. Momentum and revolution in organizational adaptation. Academy of Management Journal, EUA, v. 23, n. 4, p. 591-614, 1980.

7. DRUCKER, P. The coming of the new organization. Harvard Business Review, Boston, v. 66, n. 1, p. 45-53, Jan./Feb. 1988.

8. CAMERON, K. Investigating organizational downsizing: fundamental issues. Human Resource Management, EUA, v. 33 , n. 2 , p. $183-88$, Summer 1994

9. The anorexic corporation. The Economist, London, v. 3 , p. 19-20, Sept. 1994; When slimming is not enough. The Economist, London, v. 3, p. 5960, Sept. 1994.

10. STONE, G. When Prozac fails, electroshock works. New York Magazlne, New York, v. 14, p. 55-9, Nov. 1994; TWOMBLY, R. Shock therapy returns. New Scientist, EUA, v. 141, n. 1915 , p. 5-21, Mar. 1994.

uase banido do meio médico no passado, o eletrochoque está voltando. Também conhecido pela sigla ECT (de terapia eletroconvulsiva), o eletrochoque é um tratamento administrado em pacientes com depressão profunda e em certos casos de esquizofrenia - doença caracterizada pela perda de contato com a realidade.

Uma corrente elétrica de baixa intensidade é aplicada na região das têmporas, induzindo uma convulsão que dura cerca de um minuto. $O$ efeito terapêutico vem da convulsão e não do choque. A convulsão interfere na liberação de neurotransmissores no cérebro. A premissa é de que, em algumas doenças, o equilibrio dessas substâncias - responsáveis pela comunicação entre as células do sistema nervoso - esteja afetado.

O tratamento teve origem no pressuposto - errado - de que esquizofrenia e epilepsia não poderiam coexistir no mesmo paciente. Daí a idéia de provocar convulsões para obter a cura para a esquizofrenia. Na década de 40, o eletrochoque transformou-se na principal forma de tratamento médico para doenças mentais. Essa popularidade levou ao uso da técnica em casos em que não havia nenhuma eficácia comprovada. Aplicado em condições inadequadas de intensidade e duração da corrente elétrica, o tratamento provocava dor, fraturas de ossos, perda de memória e outras seqüelas. Com o surgimento dos antidepressivos na década de 60, o tratamento foi praticamente aposentado.

Mas alguns estudos recentes têm demonstrado sua eficácia no tratamento de depressões profundas. Administrado em doses controladas e com o apoio de tranqüilizantes e relaxantes musculares, o eletrochoque tem demonstrado capacidade de cura. Não faltam depoimentos de ex-doentes afirmando ter reconquistado o prazer de viver.

As semelhanças com certas metodologias de intervenção organizacional são apenas coincidências. Ou não?

Há pelo menos dez anos as organizações vêm experimentando uma febre de processos radicais de mudança (PRM) ${ }^{1}$. Palavras como downsizing ${ }^{2}$ e reengineering ${ }^{3}$ tornaramse dolorosamente familiares para executi$\operatorname{vos}^{4} \mathbf{e}$ negativamente reconhecidas por acadêmicos ${ }^{5}$. Novos gurus tornaram-se ricos e famosos. Na teoria, as abordagens tradicionais sugerem que as organizações evo- luem alternando períodos de mudanças incrementais com períodos pontuados por mudanças qualitativas ou revolucionárias. Nos círculos gerenciais, esse princípio descritivo parece ter se tornado um pressuposto prescritivo para intervenções organizacionais ${ }^{7}$. Por outro lado, muito pouca pesquisa acadêmica tem tratado os pressupostos dessas abordagens ${ }^{8} e$, conseqüentemente, muito pouco é conhecido e divulgado sobre as conseqüênciaś e implicações dessas práticas para as organizações. Não obstante, elas parecem continuar praticando este tipo de mudança continuamente, quase que compulsivamente?

A tese apresentada neste trabalho é que tais metodologias são técnicas de alto risco para a transformação de organizações e que as conseqüências a médio prazo são praticamente desconhecidas. Embora a maioria dessas metodologias focalize o processo de transformação, poucas têm dado atenção à natureza, extensão e gravidade das rupturas provocadas. Essas dimensões do processo de intervenção são usualmente deixadas para os sobreviventes da mudança e, significativamente, nunca são tratadas pelos gurus do tema.

Este trabalho originou-se dessa preocupação com os resultados desconhecidos e potencialmente negativos das mudanças radicais. Por outro lado, sua criação tem relação direta com artigos publicados recentemente sobre o retorno da terapia eletroconvulsiva (ECT) no tratamento de indivíduos com problemas de depressão ${ }^{10}$. Quando um tema - PRM e suas conseqüências - foi ligado ao outro - ECT e seus efeitos colaterais - , uma ponte cognitiva foi instantaneamente criada. No decorrer do trabalho, com a busca pelos desdobramentos da relação inicial e a construção de uma análise teórica mais bem fundamentada, optou-se pela utilização do conceito de identidade organizacional como metáfora-raiz, além do raciocínio analógico como gerador de insight, para examinar o modismo dos PRM.

O trabalho está estruturado da seguinte forma:

- na primeira seção aborda-se o conceito de identidade;

- na segunda seção procura-se justificar a utilização de metáforas em estudos organizacionais, sugerindo-se o uso do conceito de identidade como metáfora-raiz; 
- na terceira seção utiliza-se tal metáfora em conjunto com o raciocínio analógico para analisar os PRM;

- na seção final realiza-se um sumário do trabalho e procura-se indicar direçōes para futuras pesquisas.

\section{O CONCEITO DE IDENTIDADE ORGANIZACIONAL}

O uso original do conceito de identidade é tão antigo quanto a lógica. O emprego mais popular do termo vem da filosofia clássica e traz a noção de identidade associada à de self, ou seja, a permanência, a singularidade e a unicidade do que constitui a realidade das coisas. Dessas duas origens principais - lógica e filosofia clássica -, a idéia de identidade tornou-se universal, ganhando diferentes significados ao longo do tempo. Sua aplicação tornou-se tāo difundida e sua utilização atingiu áreas tāo diversas, que esses diferentes significados hoje pouco têm a ver uns com os outros.

Fora do campo da lógica, parece razoável afirmar que a idéia de identidade é aplicada a algo que descreve ou compreende o indivíduo. A noção psicanalítica de identidade individual foi a mais influente nas ciências sociais. Neste campo, a identidade individual é usualmente percebida como a classificação do self que identifica o indivíduo como reconhecidamente diferente dos demais, e similar a membros da mesma classe ${ }^{13}$. No âmbito das ciências sociais - como é o caso da análise organizacional - o conceito de identidade tem sido aplicado como metáfora no estudo de outros objetos, como grupos étnicos e nações.

\section{Uma primeira distinçăo: o objeto focal}

Entre as múltiplas perspectivas de utilização do conceito de identidade como metáfora, uma distinçāo básica pode ser feita utilizando-se seu objeto focal. Isto é, podemos distinguir as diferentes aborda- gens definindo o objeto sobre o qual o conceito é utilizado. Embora a maioria das abordagens se concentre no foco mais popular - da identidade individual —, algumas abrangem diferentes focos, variando do objeto mais específico ao mais genérico (ver figura 1 ).

A analogia entre identidade individual e identidade organizacional foi esboçada por Albert e Whetten ${ }^{12}$. A partir das noçöes de Erikson sobre identidade individual $e$ dos primeiros trabalhos sobre cultura e simbolismo, esses autores sugeriram que as organizaçōes também possuem uma identidade, ou um caráter central. Na sua definição, a identidade organizacional compreende as crenças partilhadas pelos indivíduos sobre o que é a. central, b. distintivo e c. duradouro na organização. Esses três critérios são necessários e suficientes para definir identidade organizacional como conceito científico ${ }^{13}$.

\section{Uma segunda distinção: a definição de identidade}

Uma segunda distinção básica entre as diversas perspectivas sobre identidade pode ser feita especificando-se como a identidade é definida. Isto é, se o conceito se refere a um atributo definido interna ou externamente à entidade analisada (ver figura 2).

Tomando como objeto focal a identidade individual, temos que, num extremo, a definição de identidade representa o que o indivíduo é (self), enquanto, no outro, representa como o indivíduo é visto pelos demais (imagem).

Cada uma das definiçōes mostradas na figura 1 gera diferentes conceitos de identidade, cada um representado por diferentes teorias.

\section{Combinando as duas dimensóes:} construção de um quadro de análise ${ }^{14}$

Combinando-se as duas dimensōes de objeto focal e definição de identidade - , chega-se a uma variada gama de abor

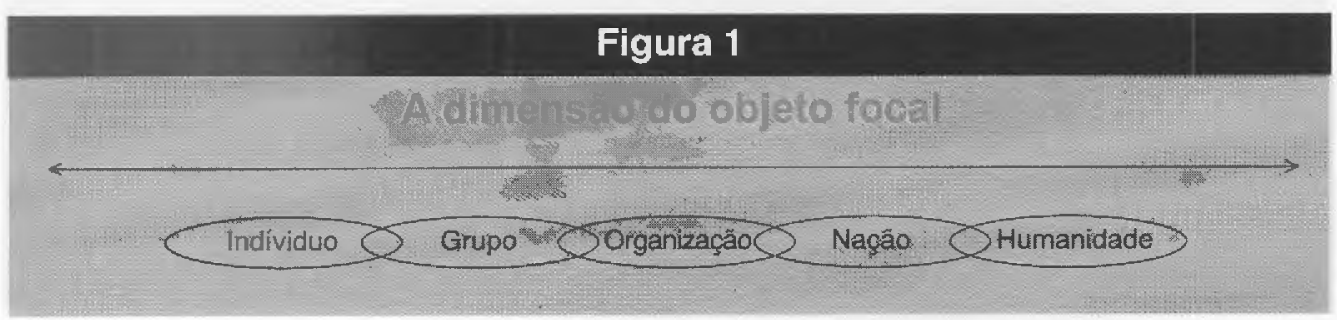

11. ERIKSON, E. Identity, youth and crisis. New York: W. W. Norton \& Company, 1968; Identity and the life cycle. New York: W. W Norton \& Company, 1980

12. ALBERT, S., WHETTEN, D. A. Organizational identity. In: CUMMINGS, L. L., STAW, B. M. (eds.), Research in organizational behavior, v. 7 . Greenwich, CT: JAI Press, 1985, p. $263-95$

13. p. 265. A partir desta definiçẫo, outras abordagens tēm sido construídas. Ver: ASHFORTH, B. E., MAEL, F. SOcial identity theory and the organization. Academy of Management Review, EUA, v. 14. p. 20-39, 1989; DUTTON, J. E., DUKERICH, J. M. Keeping an eye on the mirror: the role of image and identity in organizational adaptation. Academy of Management Journal, EUA v. $34, \quad$ p. $366-75,1991$; KRAMER, R. M., BREWER, $M$. B. Effects of group identity on resource use in a simulated commans dilemma. Journal of Personality and Social Psychology, v. 46, p.1044-57. 1984

14. Este modelo constitui uma versāo preliminar do quadro de análise. 0 tema continua sendo objeto de pesquisa dos autores, en busca de um modelo mais completo. Ver CALDAS, M. P. WOOD, Jr. T. Identidade organizacional. Inédito. São Paulo: EAESP/FGV, 1995 
15. ERIKSON, E. Identity, youth... $0 p$, cit.; Identity and the life...Op.cit

16. As dlmensões propostas também levam a perceber como tếm sido poucas as pesqulsas realizadas neste nivel de definiçāo de identidade. Uma exceçāo é o trabalho de Diamond, cuja noçāo de identidade parece estar próxima da fronteira entre a identidade definida internamente e a identidade definida pelo comportamento. DIAMOND, M. A. The unconscious life of organizations: interpreting organizational identity. Westport: Quorum Books, 1993.

17. TAJJFEL, H., TURNER, J.C. The social identity theory of intergroup behavior. In WORCHEL, S., AUSTIN, W. G. (eds.). Psvchology of inter. group relations, v. 2, Chicago: Nelson-Hall, 1985, p. 7-24: GECAS, $V$. The self-concept. Annual Review of Sociology, EUA, v. 8, p. 1-33, 1982.

18. ASHFORTH, B. E., MAEL, F. Social identity theory and the organization. Academy of $\mathrm{Ma}$ nagement Review. EUA, V. 14 ก. 1, p. 20-39, 1989; 0'REILLY, C. CHATMAN, J. Organizational commitment and psychological attachment. Journal of Applied Psychology, EUA, v. 71, p. 49, 1986.

19. KRAMER, R. M., BREWER, M. B. Etfects of group identity... Op. cit.; BROWN, R., WILLIEMS, J. Group identification: the same thing to all people? Human Relations, v. 37, p. 54764, 1984; CHATMAN, J. Matching people and organizations. Administrative Science Quarterly, New York, v. 36, p.45584, 1991 .

20. DUTTON, J. E., DUKERICH, J. M. Keeping an eve on the mirror... Op. cit.; ELSBACH, K. D. KRAMER, R. M. Cognitive strategies for managing organizational identity: a study of business school responses to the 'Business Week' rankings. Paper presented at the annual meeting of the Academy of Management, Dallas, IX. Under revision for publication in $A d m i-$ nistrative Science Quarterly, 1994; DUTTON, J. E., DUKERICH, J. M., HARQUAIL, C. V. Organizational images and member identification. Administrative Science Quarterly, New York, v. 39, p. 239-63, 1994.

21. DUTTON J. E., DUKERICH J. M., HARQUAIL, Celia V. Organizational images and member...0p. cit.

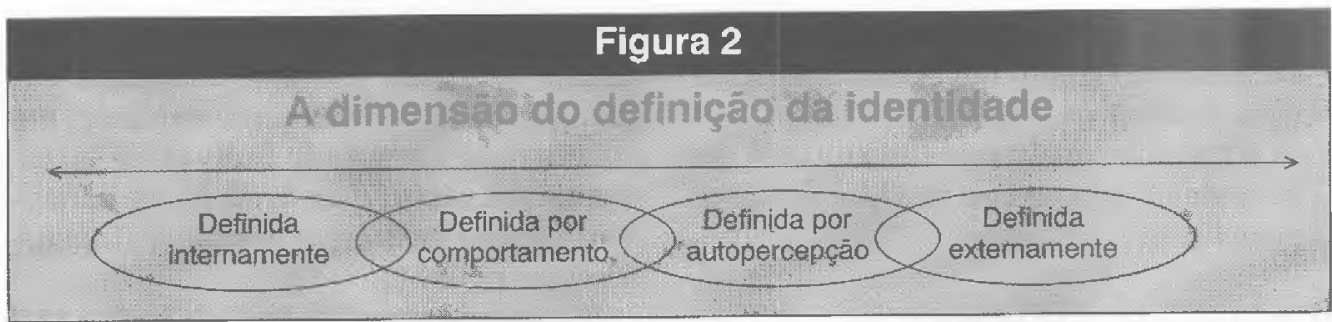

dagens para o conceito. Essas duas dimensões ajudam a ampliar a percepção de como a identidade individual e a identidade organizacional podem ser vistas. Então, tomando-se como objetos focais o indivíduo e a organização, pode-se criar um quadro de análise (figura 3 ).

Para o propósito deste trabalho, é útil exemplificar as analogias possivveis entre os conceitos de identidade individual e identidade organizacional.

Dentro da noçāo de identidade definida internamente, a figura 3 mostra que a noção de self $f^{15}$ pode ser comparável à noção de identidade organizacional. Na seção seguinte, esta analogia será aprofundada, sugerindo-se que algumas patologias que afetam a identidade individual podem ter contrapartidas no domínio organizacional $^{16}$.

Dentro da definição comportamental de identidade existem variados exemplos de perspectivas teóricas, tanto no domínio individual quanto no organizacional. $\mathrm{O}$ quadrante da dimensão individual compreende a maior parte das abordagens psicanalíticas baseadas no trabalho de Erik- son. No quadrante da dimensão organizacional, o trabalho de Albert e Whetten é, provavelmente, o mais representativo. Se a identidade individual pode ser considerada análoga à identidade organizacional, então a noção de comportamento individual pode ser comparável à de cultura organizacional - ou de seus níveis superiores. Ambas as noções denotam como algo - ou alguém - expressa o que é, e não propriamente o que esse algo - ou alguém - é.

Tomando a idéia de identidade definida pela autopercepção, chega-se a novas analogias. No domínio individual, essa definição de identidade é típica de abordagens relacionadas às correntes dominantes na psicologia social: as teorias de autoconceito ${ }^{17}$; de identidade social ${ }^{18} \mathrm{e}$ de identificação de grupos ${ }^{19}$. Do lado organizacional, esse nível compreende perspectivas que utilizam noçōes muito similares de identidade, mas aplicando-as à organização como um objeto, como as abordagens do autoconceito organizaciona $\mathrm{I}^{20}$ ou da auto-imagem organizacional ${ }^{21}$.

Finalmente, utilizando o conceito de definição externa de identidade, pode-se en-

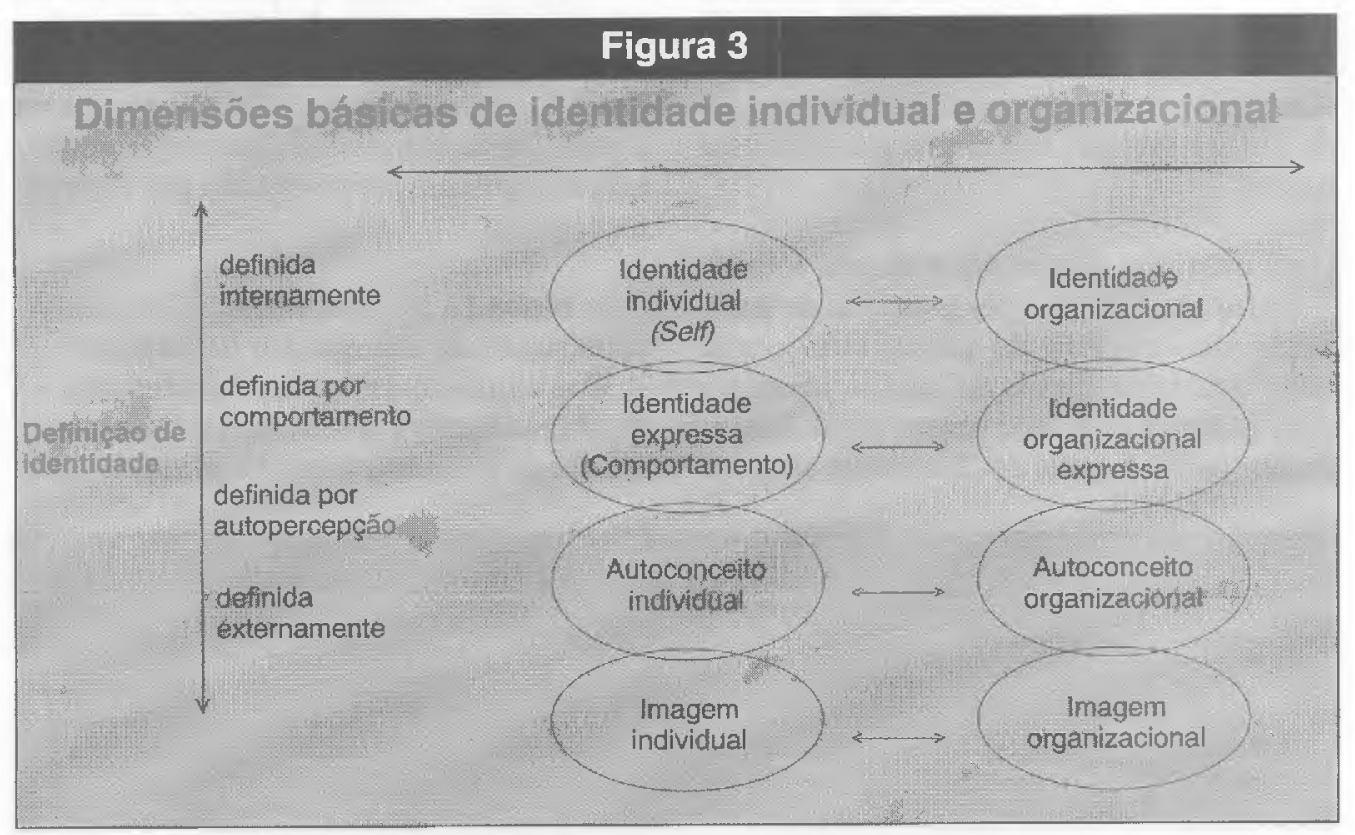


contrar as abordagens que focalizam a identidade como a imagem de indivíduos ou organizaçôes. No domínio organizacional, exemplos típicos são os trabalhos de Fombrun e Shanley ${ }^{22}$ e Garbett G. $^{23}$.

Em essência, diferentes abordagens à noção de identidade relacionam-se a diferentes conceitos e, portanto, diferentes formas de analisar organizaçōes. Neste sentido, pode-se afirmar que a identidade não deve ser exclusivamente entendida no contexto expresso por Albert e Whetten. Isto é, nāo pode ser percebida apenas como um conceito fechado, um atributo que as organizaçōes possuem. Este é apenas um dos seus múltiplos sentidos. A identidade deve ser tomada como metáfora e, como tal, gerar diferentes insights.

\section{METÁFORAS E COGNIÇÃO}

Muito mais que simples figuras de linguagem, as metáforas sāo manifestações de operaçōes cognitivas fundamentais. $\mathrm{O}$ raciocínio metafórico é uma habilidade-chave humana ${ }^{24}$. As metáforas sāo como pontes, conduzindo ligaçōes mentais de alta ordem entre entidades e expressando significados impossíveis de traduzir em linguagem literária ${ }^{25}$.

$\mathrm{O}$ conceito de metáfora-raiz identificase com a idéia de visão de mundo. Um exemplo de metáfora-raiz pode ser encontrado na análise de Foucault da história européia. Para fixar as fronteiras das diversas épocas analisadas, o filósofo elege metáforas dominantes que seriam representativas de cada era. O objetivo de Foucault, no uso destas metáforas, é organizar, orientar, estruturar e limitar o objeto de estudo e o discurso teórico ${ }^{26}$.

No campo da análise organizacional, Morgan $^{27}$ é, sem dúvida, um dos grandes responsáveis pela popularizaçāo do usn de. metáforas. $\mathrm{O}$ uso de metáforas gera imagens para estudar um determinado objeto. $\mathrm{O}$ uso ideal se dá quando as diferenças entre os dois - objeto e metáfora - sāo significativas, porém não totais. O próprio autor alega que as metáforas são tanto modos de ver como modos de nāo ver e que nenhuma metáfora consegue captar a totalidade da vida organizacional.

O que se propõe no presente trabalho é que identidade organizacional seja então entendida nāo como conceito, mas como metáfora-raiz, como uma visāo referencial a ser adicionada a outras na compreensāo de fenômenos organizacionais. $\mathrm{O}$ objetivo não é explorar detalhadamente similaridades, mas sim gerar insights simbólicos, abstratos.

Outra questão pertinente é a do uso e compreensão da metáfora. De acordo com Gibbs e $\mathrm{Hall}^{28}$, a intenção do proponente, ao sugerir ou utilizar uma metáfora, é a peça-chave para entender seu sentido. $\mathrm{O}$ entendimento, portanto, envolve a descoberta de um sistema de pontos comuns associando, por relações assimétricas, a metáfora ao objeto. $\mathrm{O}$ entendimento passa igualmente pelo reconhecimento, por parte do receptor, da intenção do autor ao fazer tal declaração. Neste sentido, a idéia de utilizar identidade como metáfora-raiz para analisar as organizações, apesar de útil, é também limitada pelas restrições do raciocínio metafórico. De fato, quando uma metáforaraiz se torna tão abstrata para analisar eventos, um simples raciocínio analógico pode ser uma ferramenta mais útil.

\section{A ERA DAS MUDANÇAS CONVULSIVAS}

A proposta deste trabalho é investigar certos aspectos dos PRM. A analogia original proposta - associando identidade individual e identidade organizacional pode ser o ponto de partida para uma segunda analogia, entre os PRM e a ECT. Aliás, essa segunda associação chega a ser instintiva. Parece razoável retratar as mudanças que as organizaçôes vêm sofrendo nos últimos anos, como uma onda interminável de choques e convulsões ${ }^{29}$. $\mathrm{O}$ argumento é que ambas as metodologias a ECT e os PRM - podem ser consideradas 1. modismos, 2. perigosas, e 3. autoilusórias.
22. FOMBRUM, C., SHANLEY, M. What's in a name? Reputation building and corporate strategy. Academy of Management Journal, EUA, v. 33, p. $233-58,1990$

23. GARBEIT, T. How to build a corporation's identity and project its image. Lexington, MA: D.C. Health and Company, 1988.

24. BECK, B. E. F. Metaphors. cognition and artificial intelligence. In: HASKELL, R. E. (ed.) Cognition and symbolic struc tures: the psychology of metaphoric transformation. Norwood: Ablex, 1987.

25. GIBBS, Jr. R. W., HALL, C.K. What does it mean to say that a metaphor has been understood? In: HASKELL, R. E. (ed.) Op. cit.

26. A este respeito, ver HASKELL, R. E. Giambatista vico and the discovery of metaphoric cognition. Op. cit.

27. MORGAN, G. Paradigms, metaphors and puzzle solving in organization theory. Administrative Science Quarterly, New York, 25, p. 605-22, 1980; images of orga nization. Newbury Park, CA: Sage, 1986

28. GIBBS, Jr. R. W., HALL, C. K. What does it mean... Op. cit.

29. WOOD JR, T., CALDAS, M. P. A volta do tratamento de choque. RAE Light, v. 1, n. 4, p. 1315, set./out. 1994. 
30. Idem, ibidem.

31. TAYLOR, F. W. Scientific management. New York: Harper \& Row, 1947 \{1911\}; FAYOL, H. General and Industrial management. New York: Pitman, 1949 (1916).

32. ScoT, W. R. Organizations: rational, natural and open systems. 2 ad. Englewood Cliffs, NJ: Prentice Hall, 1987.

33. HALL, R. Organizations, structure and process. Englewood Cliffs, NJ: Prentice Hall, 1977.

34. MAYO, E. The social problems of an industrial civilization. Cambridge, Mass. Harvard University Press, 1945; MACGREGOR, D. The human side of the enterprise. New York: McGraw-Hill, 1960.

35. EMERY, F. E, TRIST, E. L. Socio-techinical systems. In: CHURCHMAN, C. W., VERHULST. M. (eds.) Management science models and techniques. v. 2, EUA: Pergamon, 1960.

36. LIKERT, R. New paterns of management. New York: McGraw-Hill, 1961.

37. ARGYRIS, C. Interpessoa! competence and organizational effectiveness. Homewood, III.: Dorsey Press, 1962.

38. PERROW, C. Complex organizations: a critical essay. 3. ed. New York: McGraw-Hil, 1986.

39. BURNS, T., STALKER, G. M. The management of innovation. New York: Barnes \& Noble, 1961; WOODWARD, J. Industrial organization: theory and practice. London: Oxford University Press, 1965.

40. ANSOFF, H. I., DECLERCK, R. P., HAYES, R. L. From strategic planning to strategic management. New York: Wiley, 1974.

41. DRUCKER, P. The emerging theory of manufacturing. Harvard Business Review, Boston, v. 68, n. 3 , p. $94-102,1988$; GEHANI, R. R. Quality valuechain: a meta-synthesis of frontiers of quality movement. Academy Management Executive, EUA, v. 7, n. 2, p. 29-42, 1993.
Navegando as ondas da mudança organizacional

Em termos práticos, quando pensamos em terapia organizacional, as semelhanças entre as técnicas populares atuais e a terapia de choque vão além de mera coincidência. Observando a evoluçāo das duas metodologias, paralelos interessantes podem ser traçados ${ }^{30}$.

As primeiras técnicas de mudança organizacional enfocavam quase que exclusivamente a estrutura formal da empresa ${ }^{31}$. Engenheiros e outros agentes, dotados de forte orientação mecanicista, desenhavam, em prancheta, novas configuraçôes de trabalho. Isso envolvia modificaçöes nas relações hierárquicas e a criação, alteração ou exclusão de funções. As peças que não funcionavam eram substituídas. O que importava era reprojetar racionalmente a empresa, entendida essencialmente pela sua estrutura e processos formais ${ }^{32}$. Mas o maior trabalho acabava sendo o gerenciamento do impacto causado pelas mudanças. Não raras vezes, estas mudanças sucediam-se com tal frequência que se tornava impossível avaliar seus efeitos ${ }^{33}$.

Com o esgotamento gradativo desse modelo, vitimado por seus insucessos práticos, as técnicas de mudança organizacional passaram a enfocar mudanças nas pessoas e suas relaçôes ${ }^{34}$. É o segundo momento das terapias organizacionais. A abordagem sociotécnica ${ }^{35}$, as dinâmicas de gru$\mathrm{po}^{36}$, os workshops de sensibilização e o desenvolvimento organizacional ${ }^{37}$ foram algumas das ondas desse segundo momen-

\section{Quadro 1}

"Desta vez é diferente." No campo das ciências médicas, a ECT tem sofrido críticas por sua natureza medieval' ${ }^{\dagger}$. Por outro lado, seus defensores advogam que, atualmente, algumas drogas podem facilitar o tratamento. De certa forma, isto é o mesmo que afirmar que o taylorismo - entenda-se aqui estudos de tempos e movimentos - pode ser revisitado porque atualmente existem melhores cronômetros. Sob esse prisma, as conseqüências a médio e longo prazos das duas formas de intervençāo permanecem encobertas.

"Casualidades menores." Os defensores da ECT também advogam que esta técnica e os antidepressivos sāo as únicas formas disponiveis para diminuir o sofrimento de milhares de pessoas afetadas por severas depressôes. Nesse sentido, seria mesmo imoral mantê-los nesse estado por causa de efeitos colaterais menores ou apenas potenciais ${ }^{2}$. Argumento similar é apresentado pelos to. O foco foi deslocado para o comportamento e o clima organizacional. Partia-se do pressuposto de que a reduçắo do nível de conflito e a melhoria das relações entre as pessoas poderiam melhorar o desempenho das empresas ${ }^{38}$.

Num terceiro momento, teóricos começaram a valorizar o ambiente como determinante-chave das mudanças. Questôes como tecnologia e competiçăo governariam a estratégia e a ação, e estas deveriam comandar a adaptação das pessoas, das estruturas e dos processos. O pressuposto básico era que quanto maior fosse a adequação da organização ao seu ambiente, melhor seria seu desempenho ${ }^{39}$. A mudança organizacional, nesse momento, passou a ser algo intimamente ligado ao planejamento estratégico ${ }^{40}$.

Cabe notar que o segundo e o terceiro momentos nāo foram seqüenciais. De fato, eles representam escolas de pensamento que coexistiram em diferentes tradiçōes.

O quarto momento das terapias organizacionais pode ser associado ao boom dos processos de qualidade e produtividade. Quase que de repente descobriu-se que, enquanto as empresas ocidentais melhoravam o clima organizacional e sofisticavam seus processos de planejamento estratégi$\mathrm{co}$, suas congêneres japonesas iam tomando conta do mundo dos negrócios ${ }^{41}$. Foi o momento de estudar as técnicas orientais de administração. Algumas delas, por ironia, eram baseadas em idéias ocidentais, temperadas com altas doses de disciplina e comprometimento com o trabalho. $\mathrm{O}$

\section{Argumentos mais importantes dos deft}

apóstolos dos PRM. A questâo da competitividade, como uma cruzada sagrada, justificaria todas as casualidades menores. Está implícito que, sem o tratamento, o paciente não sobreviverla. Mas é sabido que nem todos os pacientes reagem da mesma forma e positivamente a medicamentos. Similarmente, nem todos os processos realizados pelas organizaçōes encontram um final feliz. Além disso, os riscos parecem aumentar quando o tratamento é empregado indistintamente, mais pelo seu caráter de modismo e menos pela indicaçāo de um diagnóstico adequado.

"Resultados inegáveis." Muitos defensores da ECT - em casos psiquiátricos críticos - afirmam que o tratamento funciona tāo bem que muitos pacientes dizem ter "reconquistado o prazer de viver $r^{33}$. Similarmente, defensores dos PRM advogam que mais e mais organizaçōes estâo adotando essa abordagem, e algumas estão regularmente 
mundo empresarial pareceu virar-se para os processos de manufatura just-in-time, a qualidade total e a orientação para o cliente. Algumas palavras antes exóticas, como kanban e kaizen, tornaram-se parte obrigatória do discurso gerencial. Neste momento, o pressuposto era que as mudanças não poderiam ser vistas como eventos isolados, mas sim como processos de melhoria contínua ${ }^{42}$.

As técnicas e as metodologias dos momentos anteriores foram absorvidas, mas sempre subordinadas ao processo maior. As estruturas continuaram a ser reprojetadas e as pessoas continuaram a ser sensibilizadas, mas como parte ou consequiência das mudanças, e nāo como um fim em si mesmo. As alteraçōes de estruturas e processos passaram a ser socialmente corretas. É o ápice das estruturas matriciais, das redes orgânicas, das organizações flexíveis e do participacionismo. É também o momento da cultura organizacional, que ganha no ambiente gerencial uma conotação própria ${ }^{43}$, com uma crença de que a construçāo de valores compartilhados e a intervençāo em comportamentos fossem capazes de gerar impactos positivos no desempenho ${ }^{44}$.

Este quarto momento prosseguiu até que se notou, num contexto de crise econômica, que a questāo essencial da competitividade não estava ainda resolvida. Notou-se que esta busca passava por alteraçōes radicais nas empresas: não apenas por incrementos quantitativos, mas por saltos qualitativos. Por mais kaizen que se praticasse, os japoneses continuavam a fa- zer produtos melhores e mais baratos. $\mathrm{E}$ quando não faziam, encomendavam aos coreanos, tailandeses ou outros tigres.

Foi então que, no âmbito das organizaçóes, a terapia de choque voltou com carga total. Voltou um pouco mais amadurecida, entendendo a importância de cooptar as pessoas, para que elas próprias ligassem a chave. Voltou mais sensivel à questão da competitividade e da qualidade total. Voltou admitindo que, após a convulsão do choque, os conceitos de melhoria contínua deveriam ser retomados ${ }^{45}$. Mas voltou sem abrir mão da crença no imperativo da mudança radical e na capacidade dos tratamentos de choque.

Esse tipo de terapia reapareceu com os processos de downsizing e com os cortes em massa de pessoal —, especialmente a média gerência ${ }^{46}$. Foi nesta onda que o mundo empresarial passou a falar em reengenharia $^{47}$. Como dizem os evangelistas desta (nem tão) nova abordagem, a questão não é consertar a organização; é preciso jogar fora o que existe e reinventar a empresa a partir do zero. E esse reinventar parte dos processos principais da organização, não da hierarquia e estrutura existentes. Assim como os defensores do eletrochoque acreditam que é necessário provocar convulsóes para curar ou amenizar processos esquizofrênicos ou de depressão crônica, os apóstolos da reengenharia anunciam que é preciso provocar choques profundos para implementar mudanças efetivas e conseguir a cura para a falta de produtividade.

\section{sores da terapia eletroconvulsiva e dos PRM}

reinventando-se. Nos processos de mudança organizacional, as abordagens radicais sáo, de fato, adotadas umas após as outras ${ }^{4}$. As razōes sāo đuas: primeiro, porque isso legitima opapel dos gerentes como geradores de açōes; ${ }^{5}$, segundo, porque isso os confirma como líderes, grandes empreendedores na implementaçāo de tendênciass inovadoras. Mas, como um todo, as organizaçöes podem ficar tāo entretidas com os processos de aplicar metodologias e sobreviver a elas, que isso acaba se tornando um vicio, sobrando pouca energia para suas atividades essenciais

"Efelto colateral temporário, alívio a longo prazo." Os defensores da ECT advogam que o único efeito colateral conhecido é uma perda temporária de memória. Nas organizaçóes, por outro lado, os efeitos colaterais ainda säo muito pouco compreendidos. De qualquer forma, entre os efeitos dos PRM também está uma perda da memória orga- nizacional. Convém aqui lembrar que a memoria, tanto para o indivịduo como para a organização, è um elemento-chave, gue afeta a capacidade de raciocínio e aprèndizado.

1. STONE, G. When Prozac fails, electroshock works. New York Magazine, New York, v. 14, p. 55-9, Nov. 1994

2. FINK, M: Convulsive therapy: theory and practice. New York: Raven Press, 1979.

3. TWOMBLY, R. Shock therapy returns. New Scientist EUA, V. 141. 17. 1915, p. 5-21, Mar. 1994.

4. Em alguns casọs, organizaçōes chegam até a ądotá-las simultaneamente.

5. STARTBUCK, W. H. Organizations as action generators. American Sociofogical Review, EUA, v. 48, p. 91-102, Feb. 1983.
42. DEMING, W. E. Out of crisis. Cambridge, MA: MIT, 1986: YOUNG, S. A framework for sucessful adoption and performance of Japanese manufacturing practices in the Unites States. Academy of Management Review, EUA, v. 17, p. 677 $700,1992$.

43. DEAL, T. E. KENNEDY, A. A Corporate cultures. Reading, Mąss: Addison-Wesley, 1982.

44. TRICE, H. M., BEYER, J. M. Studying organizational culture through rites and cerimonials. Acaderny of Management Review, EUA, v. 9, ก. 4, p. 653-69, 1984.

45. DAVENPORT, Y. H. Need radical innovation and continuous improvement? Integrate process reengineering and TQM. Planning Review, EUA, v. 22, ก. 3 p. $6-12,1993$.

46. CAMERON, K., FREEMAN S., MISHRA, A. Downsizing and redesigning... Op. cit.; TOMASKO, R. Downsizing: reshaping the corporation Op. cit

47. HAMMER, M. Reengineering work: don't...Op. cit 
48. ABRAHAMSON, E. Managerial fads and fashions: the diffusion and rejection of innovations. Academy of Management Review, EUA, v. 18, $\mathbf{p}$. 487-517, 1991; CALDAS, M. P., WOOD Jr, T. Inovações gerenciais em ambientes turbulentos. In: WOOD JR., T. (coord.). Mudança organizacional: aprofundando temas atuais emadministraçāo de empresas. Sāo Paulo: Atlas, 1995.

49. GIILL, J., WITTLE, S. Management by panacea: accounting for transience. Journal of Management Studies, Reino Unido, v. 30 , n. 2, p. 281-95 1992.

50. Idem, ibidem.

51. Quando já existe uma massa crítica de adotantes, outras organizaçōes passam a adotar determinado modismo mais por pressão do meio que por escoIha racional. Ver ABRAHAMSON, E. Managerial fads and fashions.... Op. cit.
Adaptação a uma era radical: o modismo da mudança

Nesta era das empresas ágeis e flexíveis, novos gurus despontaram do anonimato, trazendo a bandeira da mudança radical. Trata-se, sem dúvida, de um retorno aos dias em que os engenheiros buscavam mudar organizações rabiscando organogramas, acreditando que assim poderia ser operada uma mudança planejada. A diferença é que os novos mestres da mudança agora advogam o reprojeto dos processos.

A febre atual por tais metodologias está claramente ligada ao fato de que vivemos uma era na qual tudo é subordinado à questão da competitividade. O mundo empresarial contemporâneo é uma terreno fecundo para a proliferação de novos modismos $^{48} \mathrm{e}$ a reciclagem de velhas práticas. Essas metodologias são normalmente geradas, utilizadas e descartadas como panacéias gerenciais, seguindo um ciclo similar ao ciclo de vida de um produto ${ }^{49}$. Se tal raciocínio for correto, as organizaçóes verão estas ondas passarem, uma após a outra. A ideologia gerencial parece recusar-se a aceitar a complexidade, pulando de modismo em modismo sem considerar momentos de reflexão e avaliação crítica ${ }^{50}$. A mudança organizacional, neste contexto, torna-se uma busca constante por soluçōes imediatistas. Neste sentido, cria-se uma forte tendência ilusionista, uma vez que cada modismo traz em seu bojo seus próprios critérios de sucesso. Reflexões mais profundas esbarram no comprometimento dos patrocinadores dos processos e nas redes de poder instaladas nas organizações.

Navegando no quadro de análise: como as terapias radicais afetam a identidade

É possível agora retornar às duas dimensões básicas do conceito de identidade propostas na figura 3, utilizando-as para entender como as mudanças radicais afetam a identidade. Por exemplo: tomando-se a segunda coluna - da organização como objeto focal - e explorando as idéias geradas a partir de identidade como conceito externamente definido a conceito internamente definido, podem-se elaborar os seguintes raciocínios:

- partindo do pressuposto de que, em muitos casos e a partir de um certo estágio, a adoção de modismos se dá por mimetis$\mathrm{mo}^{51}$, pode-se afirmar que um ponto es- sencial para a adoção de um modismo é a imagem, ou seja, como a organização é percebida pelo meio ambiente - quarto quadrante;

- uma vez adotado o modismo e iniciado o processo de mudança, haverá um questionamento dos modelos cognitivos vigentes e da percepção que a organização tem de si mesma - terceiro quadrante. Em geral, os condutores do processo buscarāo transformar a auto-imagem positiva em negativa, apostando na dissonância entre o percebido como real e o projetado como ideal como condição para a mudança;

- num momento posterior, o processo de mudança vai operar alterações estruturais e estratégicas que gerarão impactos nos níveis mais profundos da organização, alterando suas características mais centrais - primeiro quadrante - e a expressão destas características - segundo quadrante. É o momento em que traços de cultura e identidade são afetados.

Obviamente, este processo não tem a linearidade aqui descrita. No decorrer da implementação de mudanças radicais, múltiplas interações ocorrem entre os vários níveis - quadrantes - num processo de dinâmica complexa e resultados desconhecidos.

Por outro lado, se alterarmos o rumo da navegação para o nível do indivíduo primeira coluna - abrem-se outros caminhos de análise. Pode-se, por exemplo, investigar os efeitos dos PRM nos indivíduos e na organização. $O$ processo de mudança pode, desta forma, ser estudado através da interação entre esses dois níveis, explorandose os múltiplos vetores de transformação e a resistência provocada pela mudança.

Os PRM parecem realmente ter a capacidade de afetar a identidade em vários níveis, mas fica claro que não conseguem controlar adequadamente as conseqüências das convulsões que provocam. $\mathrm{O}$ argumento é de que essas metodologias inadvertidamente interferem nas complexas redes de significado - texturas - que sustentam a organização. Obviamente, os defensores de mudanças radicais advogam que o estado atual das coisas é anacrônico, constituindo uma barreira à adequação das empresas às novas demandas do ambiente. Eles defendem a idéia de que a destruição dessas redes é não somente desejável, mas também essencial para a sobrevivên- 
cia. Mesmo tomando esses argumentos como verdadeiros - e em muitos casos eles o sāo - é inegável que tais metodologias nāo são adequadas para compreender e reconstruir tais redes de significado. Essa tarefa é quase sempre deixada aos sobreviventes da mudança. Eles é que terão de lidar com o day-after, marcado pelos efeitos colaterais e traumas do choque da mudança.

\section{A era da terapia convulsiva nas} organizaçōes: o preço de um jogo de alto risco

Muitos observadores concordam que, mesmo que a febre das metodologias radicais passe, isso nāo significa que as organizações vão sair ilesas ${ }^{52}$. $\mathrm{O}$ argumento a ser aqui desenvolvido é que, assim como a terapia eletroconvulsiva está retornando e gerando um amplo debate quanto a seus impactos sobre o indivíduo, sua contrapartida organizacional deveria ser melhor discutida. Não se pretende provar que os dois processos são idênticos, mas apenas gerar, através de uma analogia semi-estruturada e intuitiva, insights que alimentem um importante debate.

Além de terem caráter de modismo e serem altamente ilusórios, os PRM podem também ser perigosos. A seguir, busca-se ilustrar este ponto de vista a partir dos argumentos mais importantes dos defensores da terapia eletroconvulsiva e dos PRM (ver quadro 1).
52. SHERMAN, S. How will we ive with the tumult? Fortune EUA, v. 13, p. $123-25,1993$

\section{COMENTÁRIOS FINAIS}

Este trabalho teve origem na preocupaçāo dos autores.com a natureza e extensáo dos impactos dos PRM, tendo sido inspirado por uma analogia instintiva destes processos com a ECT. A metáfora da identidade organizacional foi empregada para fundamentar e apoiar a extensào da analogia inicial.

O propósito principal foi defender a tese de que os PRM sāo metodologias de alto risco e que seus efeitos de longo prazo são ainda desconhecidos. Cabe agora sintetizar os pontos principais desenvolvidos ao longo do texto:

- com o objetivo de ajudar a esclarecer o conceito de identidade, foi proposto um quadro de análise. O estudo da identidade deve unir campos teóricos distintos. Assim, o conceito deve ser entendido de forma plural;

em seguida, foi tratada a questão das metáforas e da metáfora-raiz da identidade. $O$ argumento aprèsentado é de que o raciocínio metafórico é um recurso válido e valioso no estudo das organizaçōes. Fớ tambèm discutida a noção de metáfora-raiz, da qual podem derivar outras metáforas e analogias;

- a seçāo seguinte procurou aplicar a metáfora da identidade para entender melhor o objeto de análise: o modismo dos PRM. Os principais insights gerados derivaram da analogia entre esses processos e a ECT. Em última análise, a ądoção de tais metodologias parece ser um sintoma da racionalidade vigente em nossos dias que nega a complexidade da realidade e favorece açóes simplistas e superficiaiš.

\section{Futuras pesquisas}

Os autores acreditam que estas posiçōes nằo esclarecem por completo as dimensóes mais profundas dos PRM. De fato, o trabalho acaba por levantar mais questóes do que responder, o que leva a considerar desdobramentos para futuras pesquisas.

Apesar da crença dos ąutores de que o objetivo de gerar insights sobre os PRM tenha sido cumprido, parece óbvio que a maioria das perspectivas utilizadas deve ser aprofundada. Da mesma forma, inuitas das associaçóes apresentadas foram construídas livremente. Sua validade ainda deve ser verificada.

Algumas direçōes para futuras pesquisas parecem especialmente promissoras:

entender mais claramente os efeitos colaterais dos. PRM sobre as organizaçóes;
- ampliar a utilização do recurso do raciocínio metafórico; dar continuidade à construção do quadro de análise para o conceito de identidade.

Por tudo o que foi dito anteriormente, este texto deve ser considerado, na sua essência, como work in progress. Sua estrutura, estilo gaps teóricos certamente lhe conferem um sabor "a ser completado". Os autores esperam que esta contribuição sirva de estímulo a outros pesquisadores para realizarem críticas e colaborarem no desenvolvimento do tema.

Considerando a questão da dimensão da mudança, muitos pesquisadores sugerem que rupturas podem ameaçar a identidade do grupo ou da organizaçāo'. Apesar de o impacto na identidade nāo ser completamente entendido, a analogia com o nível individual pode levantar alguns indícios. No estudo de psicopatologias, a noçāo de fragmentaçāo do self é conhecida como resultante de eventos caracterizados por ruptura profundas 2 .

$\mathrm{Na}$ tradiçāo psicanalítica, Erikson ${ }^{3}$, trabalhando em clínicas de reabilitaçāo durante a Segunda Guerra Mundial, observou que muitos dos seus pacientes haviam experimentado sensaçóes de perda de continuidade pessoal e histórica. Poderia haver uma contrapartida para a crise de identidade no domínio organizacional? É possivel afirmar que sim, desde que se pressuponha a identidade como um atributo do objeto.

De gualquer forma, a prática de mudanças radicais está crescendo e parece estar ficando cada vez mais claro que as rupturas causadas pelos processos de intervenção podem causiar conseqüências imprevisiveis e duradouras. $]$

1. DUTTON, J. E., DUKERICH, J. M. Op. cit. 1991; ELSBACH, K. D., KRAMER, R. M. Op. cit. 1994; TAJFEL, H., TURNER, J. C. The social identity theory of intergroup behavior. in: WORCHEL, S., AUSTIN, W. G. (eds), Psychology of intergroup relations. v. 2, Chicago: Nelson-Hall Publishers, 1985, p. $7-24$.

2. WOL.F. E. S. Treating the self: elements of clinical self psychology. New York: Guilford Press, 1988; NATHAN, P. E., HANIS, S. L. Psychopathology and sociefiy. ?. ed. New York: McGraw-Hill, 1980.

3. ERIKSON, E. Identity youth and crisis. New York: W. W. Norton \& Company, 1968.

\section{2}

